\title{
Diálogos entre o Norte e o Sul Global sobre violência e comunicação para a paz
}

\section{Dialogues between the Global North and South on violence and communication for peace}

\section{Diálogos entre el Norte y el Sur Global sobre violencia y comunicación para la paz}

A o refletir sobre os Estudos para a Paz (Peace Studies) e a Comunicação no Brasil, observam-se algumas oportunidades como campo científico, uma vez que, embora haja diversidade de correntes teóricas na área da comunicação no contexto da América Latina, ainda carecemos de sistematização epistemológica sobre comunicação, cidadania e cultura de paz, como afirmou nosso entrevistado, Max Vicente.

Sendo assim, a proposta de entrevistar dois especialistas - um do campo da comunicação para a paz e outro da comunicação e cidadania - nasceu da oportunidade de contribuir com esse debate no contexto latino-americano a fim de apresentar uma reflexão na perspectiva crítica da Peace Research (Pesquisa para a Paz).

Assim, a partir do Norte e do Sul global, apesentamos duas entrevistas, duas visões de contextos distintos, mas com um objetivo em comum: abrir o debate em torno da comunicação para a não violência. Cada um no seu lugar de fala. Cada um ocupando seu lugar no universo dos debates.

Foi assim que, numa manhã de primavera de 2018, na cidade de Castellón de la Plana, Espanha, a Profa. Dra. Eloísa Nos Aldás nos ofereceu um olhar amplo e dialógico sobre a comunicação para a paz (Communication for peace), campo científico consolidado no contexto dos Peace Studies.

Durante uma tarde do inverno brasileiro de 2018, na cidade de Bauru, São Paulo, Brasil, o Prof. Dr. Maximiliano Martin Vicente (Max) nos atendeu para contar sobre sua visão em torno da comunicação e cidadania e suas inter-relações com a perspectiva das Epistemologias do Sul, de Boaventura de Sousa Santos e Maria Paula Meneses, que apresenta ampla convergência de objetivos com os estudos de comunicação desenvolvidos historicamente na América Latina.

Esperamos que os leitores aproveitem o diálogo entre os pesquisadores Eloísa e Max, e que suas reflexões inspirem novas pesquisas na perspectiva crítica da comunicação e também no âmbito organizacional e das relações públicas. 


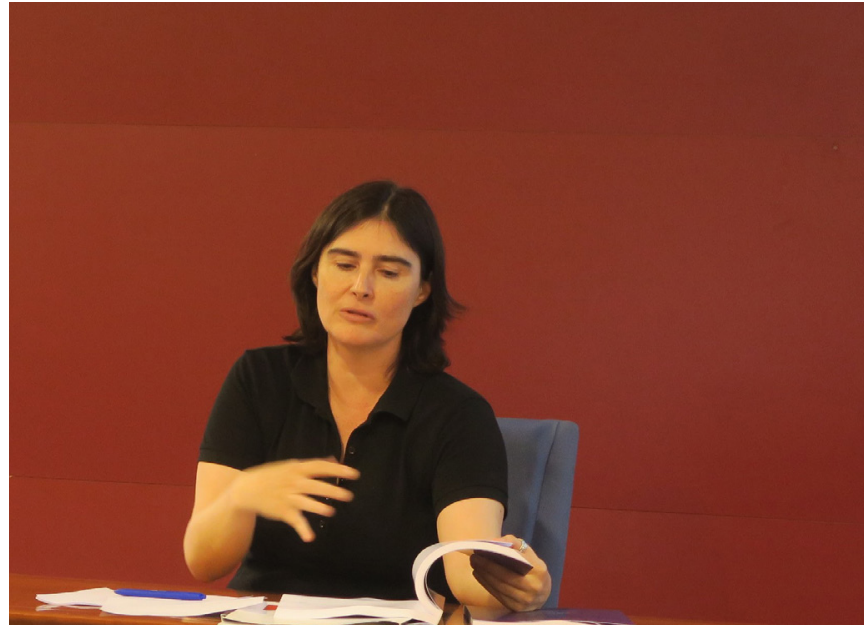

Foto: E. Aldás

\section{Eloísa Nos Aldás}

- $\quad$ Doutora em Comunicação Empresarial e Institucional pela Universitat Jaume I, Espanha

- Mestre em Literatura Comparada pela Universidade Autônoma de Barcelona e Estudos para a Paz.

Graduada em Filologia Inglesa

- Professora titular da área de Comunicação Audiovisual e Publicidade do Departamento de Ciências da Comunicação da Universitat Jaume I, Espanha

Foi diretora do Programa de Pós-graduação (Mestrado e Doutorado Internacional) em Estudos para a Paz, Conflitos e Desenvolvimento vinculado à Cátedra Unesco de Filosofia para a Paz da Universitat Jaume I

- $\quad$ Foi diretora do Instituto Interuniversitário de Desenvolvimento Social e Paz com sede na Universitat Jaume I, entre a referida universidade e a Universidade de Alicante, Espanha

- $\quad$ Autora dos livros Lenguaje publicitario y discursos solidarios: eficacia publicitaria, ¿eficacia cultural? (2007) e Comunicación y construcción de paz (2009), elaborado junto a Salvador Seguí-Cosme e Ana Maria Rivas, ambos publicados pela Editora Icaria, Barcelona

- E-mail: aldas@uji.es

\section{Maximiliano Martin Vicente}

- Doutor em História Social pela Universidade de São Paulo (USP)

- Mestre em História pela Universidade Estadual Paulista (Unesp)

- $\quad$ Graduado em História pela Universidade do Sagrado Coração (USC)

Professor do Departamento de Ciências Humanas da Faculdade de Arquitetura, Artes e Comunicação (FAAC) da Unesp

Foi livre-docente em História do Brasil em 2008

- $\quad$ Atua no programa de Pós-graduação em Comunicação Midiática da Unesp, campus de Bauru-SP, orientando pesquisas de mestrado e doutorado e ministrando a disciplina Comunicação e História na Nova Ordem Internacional

- $\quad$ Desenvolve pesquisa relacionada com o jornalismo alternativo, com ênfase no Le Monde Diplomatique

- $\quad$ Tem experiência de ensino nos cursos de Comunicação Social, na área de História do Brasil e Realidade Socioeconômica, e Política Brasileira Contemporânea.

- $\quad$ Autor do livro História e comunicação na ordem internacional, publicado pela Cultura Acadêmica - Unesp, e de artigos em revistas científicas.

- E-mail: maxvicente@uol.com.br 


\section{ANO 15 • NÚMERO 28 • 1ํㅗㅌ. 2018 • ORGANICOM}

ORGANICOM - Eloísa, considerando sua ampla experiência na área, qual éa relação entre os Estudos para a paze a Comunicação para a paz?

Eloísa - A epistemologia e as propostas dos Peace studies permitem enriquecer os enfoques das teorias da comunicação que se preocupam com a justiça social local e global. As propostas desses estudos incidem na responsabilidade e nas consequências culturais da comunicação. Especificamente, aprofundam na temática da violência cultural (em diálogo com os estudos culturais ou a sociologia), na análise de como essas violências simbólicas reforçam a violência estrutural e, por conseguinte, como ambas produzem a violência direta. Em outras palavras, apontam a performatividade dos discursos, aos efeitos e compromissos que toda interação comunicativa ou produção discursiva implica, e como podem criar e reforçar violências ou estabelecer diálogos ativos, reconstruir relações, reconhecer diferenças e incluí-las.

As principais contribuições dos Peace Studies para a comunicação são critérios e análises de exemplos para a transformação pacífica de todos os tipos de violências nas "culturas" de paz, a recuperação de outras histórias e discursos de paz positiva e paz imperfeita que trabalham a partir das mediações comunicativas com objetivos políticos coletivos. Em outras palavras, contribuem para provocar a visibilidade de todas essas estruturas e ações que produzem o sofrimento humano.

ORGANICOM - Por que no contexto dos Estudos para a Paz de caráter inter e transdisciplinar, a comunicação tem grande relevância na transformação de conflitos e desconstrução da violência?

Eloísa - Precisamente a violência simbólica e as representações constroem e influenciam nossas relações e ações e, portanto, o diálogo entre as diferentes perspectivas das ciências humanas e sociais nos permite abordar a formação e transformação desses cenários, sendo conscientes de todas as variáveis envolvidas. Necessitamos da comunicação como elemento-chave para conhecer, conectar, propor, debater e difundir propostas (mediar, em outras palavras), mas também da sociologia, da psicologia social, da educação, da tradução, das filologias comparadas, da economia, entre outras. Por outro lado, todas as disciplinas ou áreas do conhecimento necessitam revisar suas epistemologias, sua razão de ser, para que se possa refletir sobre seus efeitos sociais e culturais nas comunidades, em curto ou longo prazo, a partir da colaboração interdisciplinar, em todas as suas dimensões e interconexões, a partir da saúde pública até a convivência pacífica. Por outro lado, como muito bem reflete John Paul Lederach, a transformação de conflitos humanos tem um componente comunicativo chave em todas as suas dimensões, pois pressupõe o uso da linguagem para a compreensão das variáveis implicadas.

ORGANICOM - Muitos são os pesquisadores que contribuíram com o desenvolvimento dos Peace Studies, entre eles, Johan Galtung. Em sua opinião, além de Galtung, quais autores contribuíram com reflexões e debates-chave para a Comunicação para a Paz?

Eloísa - Muitos e muitas. É bastante difícil escolher, pois considero um trabalho de distintas comunidades de pesquisadores de comunicação e que estão em constante diálogo e reflexão entre as teorias e práticas. Às vezes denominados de Estudos para a Paz, mas outras partindo dessa interdisciplinaridade da qual estávamos falando anteriormente, o certo é que há uma grande diversidade de pesquisadores. Com certeza, deixarei de mencionar pessoas fundamentais (que me perdoem desde já), mas, para minha própria aprendizagem, eu mencionaria logo de início Vicent Martínez Guzmán, quem, a partir da "filosofia para fazer as pazes", fundamentada na ética do discurso, articula um giro epistemológico determinante para as próprias ciências sociais que nos permite também redefinir as ciências da comunicação (uma comunicação que pede responsabilidades e propõe alternativas 


\section{ANO 15 • NÚMERO 28 • 1ํㅗN. 2018 • ORGANICOM}

\section{DIÁLOGOS ENTRE O NORTE E O SUL GLOBAL SOBRE VIOLÊNCIA E COMUNICAÇÃO PARA A PAZ}

pacíficas e soluções, porque todos e todas contamos com capacidades e competências para aprender a fazer as coisas de outra forma; uma maneira intersubjetiva, que explicita nossos posicionamentos e dialoga com os demais, pois é impossível sermos objetivos; que supere as dicotomias). Nessas mesmas linhas epistemológicas, esse debate é enriquecido pelo ecofeminismo de Vandana Shiva e María Mies (e a equipe da interseccionalidade de Bell Hooks), as propostas educomunicativas de Betty Reardon e Elise Boulding, e no cenário espanhol de Manuela Mesa e os projetos do Centro de Educación e Investigación para la Paz - Ceipaz (sobretudo Visibles y Transgresoras), ou os enfoques a partir das capacidades de Judith Butler ou Amartya Sen. Ideias que também foram ampliadas por Boaventura de Sousa Santos e seu projeto Alice, incidindo no elemento-chave da interculturalidade e a incorporação de distintas lógicas e contribuições culturais chamadas de Epistemologias do Sul.

Do mesmo modo, no contexto da pesquisa-ação que teoriza as práticas, considero determinantes os trabalhos de Clemencia Rodríguez e Thomas Tufte - a primeira no âmbito da comunicação a partir das margens, o segundo na chamada comunicação para o desenvolvimento e a transformação social. Nessa linha, aqui na Espanha, no contexto da rede \#comunicambio, temos trabalhado muito para colocar a comunicação das organizações em diálogo com os movimentos sociais para transformação social a partir de propostas de cooperação, não violência e culturas de paz. Nessa perspectiva, Javier Erro, Montse Santolino, Manuel Chaparro e Víctor Marí tiveram um papel determinante para impulsionar o diálogo entre a comunicação e a tradição latino-americana de Martín-Barbero, Mario Kaplún, Rosa María Alfaro, Omar Rincón e Rossana Reguillo, entre outras também. E, nas áreas de comunicação publicitária, Marcial García López e, na perspectiva do jornalismo para a paz, Xavier Giró e Ana Fernández Viso. Além disso, também foram determinantes propostas procedentes dos movimentos globais pacifistas e de criatividade coletiva recolhidas em obras recentes como a de Andrew Boyd e David Oswald Mitchell, em Bella revuelta.

ORGANICOM - Max, muitos são os(as) pesquisadores(as) que contribuíram para o desenvolvimento dos Estudos para a Paz em âmbito global, entre eles, Johan Galtung. Em sua opinião, quais são os referentes latino-americanos que têm se aproximado da comunicação para a paz ao propor um debate crítico a respeito da comunicação para o desenvolvimento, para a cidadania ou para a transformação social no contexto da nossa realidade na América Latina?

Max - Penso que essa é, ainda, uma questão que deve ser refletida mais criticamente. Temos grandes críticos sobre 0 modelo do desenvolvimento que estão preocupados com a "importação" de ideias e exemplos alheios à nossa realidade. A Comissão Econômica das Nações Unidas para a América Latina e o Caribe (Cepal) já tratava dessa questão nos anos 1970. Destaco Ruy Marini, pouco estudado, mas que contribui com uma visão bem crítica sobre as questões do desenvolvimento e a superexploração da mão de obra, e que aponta os entraves estruturais para se obter uma política independente capaz de traçar rumos singulares e peculiares da nossa realidade. 0 mesmo podemos falar da comunicação na América Latina. MartínBarbero, Ramiro Beltrán, Marques de Melo, Guillermo Orozco e Antonio Pasquali são alguns pesquisadores entre muitos outros que poderíamos citar que elaboraram questionamentos e trouxeram temas que marcaram um percurso original no campo da comunicação na América Latina. Por outro lado, resulta impossível não destacar a figura de Paulo Freire - pedagogo brasileiro - como inspirador de modelos e interpretações nas mais diversas áreas do saber, incluindo a comunicação. Assim, podemos afirmar que temos, sim, estudos isolados relacionados com a comunicação e o desenvolvimento social, porém, quando se tenta unir esses elementos na perspectiva dos Estudos para a Paz, ainda se vislumbra um caminho bem longo para ser percorrido. Não pelo fato de não existirem estudos sobre o tema, mas porque não houve uma sistematização epistemológica sobre comunicação, cidadania e cultura de paz. Quantitativamente, os temas relacionados com a educação, cidadania e cultura de paz sobressaem na América Latina. Situações de conflitos, como o caso da Colômbia, motivaram estudos relacionados com a educação como forma de elaborar e despertar atitudes voltadas para a paz. Outro tanto pode ser dito do México e da Argentina. Tentando apontar uma direção para esses estudos e leituras feitas, poderíamos afirmar que a grande maioria das obras converge para um fator chave: propõem a mudança estrutural como condição para se estabelecer uma cultura de paz e um novo modelo de desenvolvimento e de exercício da cidadania. 


\section{ANO 15 • NÚMERO 28 • 1ํㅗㅌ. 2018 • ORGANICOM}

ORGANICOM - Eloísa, considerando sua experiência na linha da Peace Research (Pesquisa para a Paz), como é possível transformar conflitos por meios pacíficos e qual seria a responsabilidade da comunicação nesse contexto?

Eloísa - Responder essa questão excede o espaço que temos para esta entrevista. Seria um artigo completo. Há numerosos estudos que respondem essa pergunta a partir de diferentes âmbitos: Sonia París Albert, no contexto da filosofia dos conflitos, aborda a importância das percepções e da comunicação interpessoal; os manuais da Berghof Foundation ou os trabalhos de Jake Lynch, Annabel McGoldrick, Xavier Giró ou de Cristina Salas, no contexto do jornalismo; os de John Paul Lederach, como base conceitual, ou algumas contribuições interessantes sobre processos comunicativos participativos para a paz pós-conflito, de Valentina Baú.

No entanto, por contribuir com uma breve reflexão, uma educação midiática (media literacy) e uma competência comunicativa são determinantes para todos os atores nos diferentes contextos para que sejam conscientes dos efeitos de suas ações (comunicativas). A não violência é um critério fundamental tanto no nível interpessoal como na produção de discursos planejados. A comunicação atua como mediadora em todos os contextos, e os objetivos e enfoques que lhe damos - ou o quão conscientes sejamos das representações e reconhecimento mútuo ou exclusão que construímos a cada passo - determinarão as relações que estabeleceremos ou reconfiguraremos. Nesse sentido, eu gostaria de ressaltar, novamente, a gravidade da violência cultural, especialmente em relação aos discursos hegemônicos que invisibilizam relações de violência, que excluem coletivos e formas de fazer e que impedem o início de um diálogo sobre determinadas opções alternativas. Portanto, superar as tendências de "surdez social" diante de determinados problemas, os discursos herméticos de ódio em relação a determinadas comunidades ou propostas, ou estarmos preparados para debater na diversidade sem cair na desqualificação e na construção de inimigos é uma emergência comunicativa atual nos distintos contextos. O "artivismo"l e os espaços de encontro com tempo para a reconciliação são opções eficazes que estão sendo exploradas em vários lugares do mundo.

\section{ORGANICOM - No cenário internacional, os movimentos sociais são capazes de criar uma comunicação alternativa para a construção e legitimação de culturas de paz?}

Eloísa - Sim. Na realidade, eles estão sendo e sempre foram capazes. Contudo, necessitamos ponderar sobre quais termos, obviamente. Por um lado, existem comunidades, iniciativas e processos em muitos lugares que aplicam comportamentos e políticas que legitimam culturas de paz, que impulsionam economias sociais e solidárias de decrescimento econômico, mas, frequentemente, convivendo com outros contextos que não o fazem. Há muitas opções para isso e, novamente, é preciso destacar que há numerosos estudos sobre os movimentos sociais ou as chamadas organizações de movimentos sociais que teorizam sobre o tema.

Minha modesta contribuição na perspectiva da comunicação para a paz seria que a legitimação de culturas de paz - como de qualquer outro tema ou realidade - necessita, além de práticas, de articulação política em termos amplos para conseguir, do mesmo modo, transformações mais amplas. Em inglês se teoriza como advocacy, mas não somente como articulação ou incidência direta por parte de grupos específicos nas autoridades políticas e legislativas, mas também como um trabalho contínuo e em longo prazo sobre os diferentes espaços que configuram os imaginários (violência cultural ou culturas) e suas instituições (leis, decisões políticas, educação, comunicação formal massiva). Portanto, numerosos estudos recolhem as ações de comunicação política que realizaram diferentes mobilizações sociais ou organizações de movimentos sociais e suas conquistas. Não somente no contexto comunicativo (de visibilizar temas na agenda pública através de mobilizações nas ruas

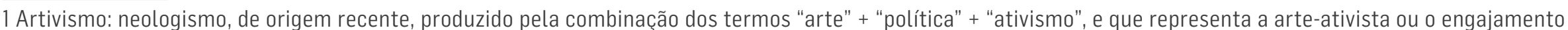

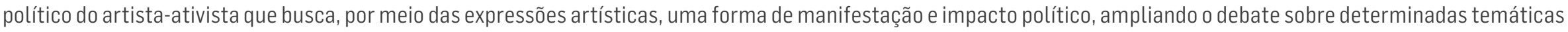
de interesse coletivo junto à opinião pública.
} 
ou o "artivismo" em outros espaços públicos, conseguir repercussão nos meios de comunicação, de informar, realizar uma pedagogia política e de cultura da solidariedade), mas também de propor mudanças de leis, influenciar decisões políticas, fazer propostas educativas... Já é possível encontrar trabalhos nessa linha, como o de Notes From Nowhere até os mais atuais que incorporam o papel das redes digitais de Victor Sampedro, Natalie Fenton, Vicent Bennet ou Tufte.

ORGANICOM - Max, considerando historicamente a dimensão alternativa da Comunicação para a Paz no cenário internacional, os movimentos sociais têm sido capazes de criar uma comunicação alternativa para construção e legitimação de culturas de paz?

Max - Com toda certeza. Se existe algo em comum na América Latina quando se fala de meios de comunicação, é a concentração midiática, tal como analisaram Guillermo Mastrini e Martín Becerra. Diante dessa hegemonia maléfica, a comunicação popular e alternativa sempre atuou tentando construir outras lógicas para entender os processos comunicativos. Os atores, as fontes, os valores e as práticas comunicacionais desses movimentos caminharam na contramão dos grupos dominantes. Daí a razão pela qual existem entraves para legitimar ou realizar concessões, conseguir financiamento para criar rádios comunitárias, jornais alternativos ou criação de sites nos quais se poderiam disponibilizar informações de interesse dos segmentos menos favorecidos socialmente. Falta uma ação coordenada desses grupos. Creio que o portal social Watch ${ }^{2}$ representa um caminho a ser seguido para fomentar atitudes que congreguem organizações alternativas destinadas a vigiar e analisar o comportamento das estruturas de poder mantidas pelo Estado. Na verdade, isso deveria estimular a união dos setores populares para ficarem mais ativos e não tão pulverizados. Sempre é bom lembrar que estamos numa sociedade marcada pelo excesso de informação, mas também pela dificuldade em conseguir informação relevante e estratégica. Creio que esse deve ser um dos grandes objetivos desenvolvidos pelas organizações alternativas: se apropriar de informação para poder estruturar seus movimentos e reivindicar ações destinadas a beneficiar os setores populares e criar outro mundo com outros valores mais próximos das necessidades da maioria da população.

ORGANICOM - Eloísa, considerando sua experiência em pesquisa sobre a comunicação de organizações não governamentais para o desenvolvimento (ONGDs), como você avalia a comunicação que produzem? Acredita que podem ser exemplos efetivos de Peace Media no caso daquelas que produzem comunicação para a transformação social?

Eloísa - A comunicação para a paz combina enfoques participativos e estratégicos. Assim, a formação em comunicação necessita de um conhecimento em profundidade desses diferentes enfoques. 0 principal é retomar enfoques coletivos, de comunicação pública, que se centrem e antecipem os processos de configuração e transformação sociopolítica e cultural, que se criem espaços de debate e ação coletiva para transformar as distintas injustiças estruturais e culturais. É determinante ampliar os indicadores e paradigmas de eficácia tradicional baseada em impactos e benefícios econômicos-privados/individualistas com conhecimentose profundidade das diferentes epistemologias e construção de identidades, partindo de critérios e indicadores de economia social, convivência, justiça social glocal. É o que eu trabalho com meus estudantes de graduação em Publicidade e Relações Públicas e os profissionais das ONGs como eficácia e eficiência cultural.

Nesse sentido - e em relação à comunicação das ONGDs no contexto do "Terceiro Setor" - é importante precisamente contribuir com a transformação social em termos de justiça global. Portanto, essas organizações, quando realmente trabalham a partir de sua cultura organizacional (que deve colocar o coletivo e objetivo comum por cima do individual e privado), as transformam em magníficos agentes comunicativos, em engrenagens para apoiar a mobilização social e os processos de pressão política necessários.

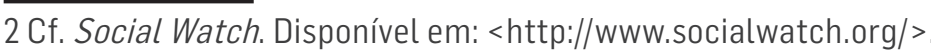


ANO 15 • NÚMERO 28 • 1ํㅗㅌ. 2018 • ORGANICOM

ORGANICOM - Max, na sua visão, como a comunicação e as relações públicas, como processo e profissão, podem contribuir estrategicamente para ampliar a construção de uma cultura de paz? A comunicação produzida pelas organizações públicas, privadas e do terceiro setor podem ser meios pelos quais se legitima a violência?

Max - Uma olhada rápida nas publicações recentes sobre comunicação mostra que estamos numa sociedade midiatizada. A título de exemplo, basta citarmos o livro de Manuel Castells, O poder da comunicação(2015) - aliás, título em português e que reflete mais claramente a que o texto se refere do que o título em espanhol - Comunicación y poder(2009). Entretanto, refletir sobre a comunicação e o poder que ela carrega nos teria que levar a propor mudanças radicais na sociedade, uma vez que o sistema em que ela se encontra inserida é desigual e nunca promoverá a igualdade. Estamos nos referindo ao capitalismo. É pura ilusão pensar que nele poderemos praticar a cultura de paz vista como um processo de transformação social. 0 mesmo digo quanto às relações públicas. Se elas têm como objeto de estudo as organizações e as instituições, devemos contextualizá-las nesse processo de implementação do sistema do capital; portanto, dificilmente promoverão a criação de uma sociedade igualitária. Contudo, nessa ótica, emerge o denominado espírito crítico e alternativo que, na verdade, nada mais faz do que evidenciar a impossibilidade de se pensar numa sociedade justa no capitalismo e nas estruturas que ele cria e que sustentam seus valores e princípios. Assim, entendo que se gera uma expectativa interessante para pensar tanto a comunicação organizacional como as relações públicas na promoção de mudanças estruturais, não conjunturais, sem as quais a cultura de paz pode minimizar problemas, mas não gerar soluções de longo prazo, que é o que se deveria buscar. Vale a pena destacar que, embora consideremos essas limitações estruturais, deve ser destacado o papel ea ação de indivíduos e profissionais, seja no âmbito da comunicação organizacional ou das relações públicas, que cada vez mais aderem às propostas da cultura de paz. Defendendo uma visão otimista, diríamos que é assim que se iniciam as transformações - grão a grão, passo a passo -e isso está acontecendo muito, como já disse, no âmbito da educação, que se caracteriza por exercer um expressivo poder multiplicador.

ORGANICOM - Eloísa, os Peace Studies começaram a se desenvolver na América Latina depois de algum tempo em que já se vinha trabalhando com Peace Research na Europa e nos Estados Unidos. Qual sua visão sobre isso?

Eloísa - Do meu ponto de vista, às vezes nos confundem as escolas e terminologias. Os Peace Studies se desenvolveram na Europa em um contexto específico de violência direta -no contexto das duas grandes guerras mundiais. No entanto, se analisamos seus objetivos, se entendemos, sobretudo, seus avanços, que atualmente focam nos saberes indígenas do Sul como fundamento e com a recuperação de filosofias, como a do bem viver ou do decrescimento, veremos que os tempos mudam. Além disso, vemos que a comunicação para a paz tem muitos pontos em comum com (e se inspira nas) propostas da comunicação participativa e comunitária latino-americana. Os contextos são muito diferentes, mas muitos dos objetivos coincidem. Em termos de comunicação, acredito que um bom exemplo é a obra Antología de comunicación para el cambio social: lecturas históricas y contemporâneas, editada por Alfonso Gumucio e Thomas Tufte, em 2008.

ORGANICOM - Max, os Estudos para a Paz começaram a se desenvolver na América Latina depois de algum tempo em que já se vinha trabalhando com Peace Research na Europa e Estados Unidos. Qual sua visão sobre isso? Quais as especificidades de nossa realidade latino-americana e as perspectivas teóricas relacionadas à transformação social no caso da América Latina (que coincidem com os mesmos objetivos dos Estudos para a Paz)?

Max - Parece-me perfeitamente compreensível que a Europa, castigada duramente por duas guerras mundiais, se debruçasse sobre os Estudos para a Paz. Os desdobramentos dessa preocupação nós já conhecemos, pois foram amplamente estudados 


\section{ANO 15 • NÚMERO 28 • 1ํㅗㅌ. 2018 • ORGANICOM}

pelos pesquisadores dos Peace Studies do velho continente e dos Estados Unidos. Agora, o que me surpreende muito e sempre me levantou suspeitas é que nós, na América Latina, tivemos atrocidades ainda maiores que as vivenciadas pelos europeus ou norteamericanos. Basta olhar quantos indígenas havia no continente americano antes do descobrimento e quantos são atualmente. Se acrescentarmos a escravidão, a exploração e a dependência econômica teremos um quadro de violência aterrorizador. A questão é que sempre se tentou ocultar esses dados, quando não se criaram versões e interpretações que simplesmente não tocam nos assuntos mais polêmicos que deveriam ser amplamente conhecidos e debatidos. Do meu ponto de vista, esse resgate é imprescindível para pensar nos Estudos para a Paz na América Latina. Existem feridas que precisam ser curadas. Nossa violência é endêmica e estrutural para os menos favorecidos, enquanto os segmentos dominantes usufruíram e usufruem benesses e regalias que em nada diferem dos países ditos desenvolvidos. Assim, discutir cultura de paz e não violência implica em resgatar essas discussões para iniciar um processo de reconstrução que vise a igualdade em todas as suas dimensões, não apenas a econômica. Paulo Freire dizia que essa tarefa é complicada e que o ideal seria retirar do oprimido o potencial que carrega como opressor; só assim se construiria uma sociedade melhor. Partindo da ótica da América Latina, a cultura de paz deve transformar e criar novos valores, muitos deles já experimentados e vivenciados pelos grupos mais marginalizados. Como lembra Boaventura de Souza Santos, os entraves a serem superados são o colonialismo, o patriarcalismo e o capitalismo. Esse poderia ser um bom caminho para os Estudos para a Paz na América Latina. Não penso que devamos ignorar as contribuições dos estudos feitos fora do continente, ao contrário, precisamos compreender essa experiência. Contudo, acredito que essas contribuições devam ser lidas e interpretadas num contexto claramente diferenciado e que implica em mudanças nem sempre pacíficas, que necessitam ser promovidas pela cultura de paz e não violência. Boaventura alerta que o Norte e o Sul global não são apenas geográficos, ambos se encontram em todos os lugares e se manifestam de diversas maneiras. É possível encontrar no Norte grupos e organizações que defendem o Sul, como vice-versa, também é certo. Em tempos de globalização, não dimensionar essa realidade seria ficar restrito a uma visão de certa forma parcial. Se a globalização tenta padronizar o mundo, também a cultura de paz deve ser globalizada.

ORGANICOM - Eloísa, qual é a relação entre a Comunicação para a Paz e os temas da educação, gênero, meio ambiente, migrações, ONGDs, entre outros, que buscam na comunicação uma estratégia de desconstrução da violência nesses âmbitos? Por que a comunicação é estratégica nesses contextos?

Eloísa - Todas essas áreas de atuação são interdependentes e devem ser abordadas na relação umas com as outras. 0 trabalho de comunicação em longo prazo, a partir da pedagogia e da articulação política, da denúncia da origem das violências e do debate e propostas de soluções, são determinantes. Em cada um desses âmbitos, existe um importante problema que deixa de fora as causas das violências, seus responsáveis e a forma de erradicá-las, e se centra nos efeitos parciais e mais estéreis para sua transformação. Nesse sentido, considero como leitura obrigatória os documentos Vademécum para una Información Internacional Responsable, que foi elaborado pela Red Dev Reporter Network sobre esses aspectos, assim como o Guía de Comunicación Movilizadora do Projeto Hambre da Fundación Quepo.

ORGANICOM - Max, partindo de uma visão latino-americana sobre os estudos de comunicação, na sua opinião, qual é a relação entre a comunicação para a paz e os temas da educação, gênero, meio ambiente, migrações, ONGDs entre outros que buscam na comunicação uma estratégia de desconstrução da violência nesses âmbitos? Por que a comunicação pode ser estratégica nesses contextos?

Max - A comunicação social - como o próprio nome já referencia - se destina a tornar públicos acontecimentos, informações, eventos, entre outros. 0 ponto-chave é que ela não é neutra e, normalmente, junto aos dados e informações que nos oferece, 
inclui valores, mesmo que seja de forma subjetiva. Recuperemos que quem detém o controle da comunicação nas nossas sociedades são oligopólios com o poder de interferir no cotidiano, criando versões e apresentando fatos do seu interesse. Ao discutir meio ambiente, por exemplo, posso manipular dados, o que geraria interpretações parciais. Da mesma maneira, podem agir os grupos alternativos, pois partem de outra concepção e têm outra finalidade. Observemos que o procedimento adotado tanto pelos oligopólios como pelas associações alternativas é o mesmo: 0 uso da comunicação como forma de se expressar e dar publicidade aos seus ideais. Sempre é bom lembrar que o silêncio é uma forma de violência, e que ao não se abordar determinados temas estamos contribuindo para que essa violência se perpetue. Na medida em que os grupos denominados alternativos foram se organizando, despertaram temas e situações "não previstas" pelos meios de comunicação massivos. Assim, nas últimas décadas, vimos entrar em pauta temas novos como os enunciados na questão. 0 que isso significa? $\mathrm{Na}$ verdade, que além das transformações estruturais, no cotidiano, devem se realizar intervenções para aceitar a alteridade sem a qual não se inicia o processo de construção para uma cultura de paz.

ORGANICOM - Eloísa, outro tema que pode ser debatido na perspectiva da cultura de paz é a interculturalidade. Entendemos que é uma dimensão de interação, de contato com distintas culturas. Na maioria dos processos migratórios é possível identificar inúmeros benefícios, mas também diversos conflitos. Como pensar a comunicação como um processo para colaborar com a mediação de conflitos interculturais?

Eloísa - A forma de nos relacionarmos com os demais depende do contexto identitário no qual nos posicionamos. Os discursos hegemônicos sobre o outro se construíram, tradicionalmente, a partir de imaginários de cultura da defesa, das fronteiras, no lugar da hospitalidade, das relações cosmopolitas ou do enriquecimento mútuo a partir da convivência. Esse tema está relacionado com o que comentávamos anteriormente sobre a falta de uma educação e comunicação que nos prepare para lidar com nossas vulnerabilidades, para saber viver nossa fragilidade sem medos, a partir da colaboração e dos cuidados. Um trabalho recente que aborda a temática na mesma linha das pesquisas para a paz e estudos de gênero - partindo da agência mútua e da resistência pacífica - é Vulnerability in resistance, de autoria de Judith Butler, Zeynep Gambetti e Leticia Sabsay, publicada em 2016 pela Duke University Press. Além desse debate, a filosofia para a paz também tem tratado a questão. Um exemplo muito interessante, também de uso da comunicação como alternativa à violência cultural, estrutural e direta em temas de interculturalidade e migrações, é o Stop Rumores.

ORGANICOM - Max, considerando a intensificação dos processos de mundialização, um dos temas mais urgentes que se destaca na atualidade se refere às migrações e interculturalidade. Na maioria dos processos migratórios, é possível identificar inúmeros benefícios para as diversas culturas envolvidas, mas também diversos conflitos e graves problemáticas sociais. Na sua visão, como pensar a comunicação como um processo para colaborar com a mediação de conflitos interculturais?

Max - Concordo com a afirmação de que as migrações transnacionais aparecem como um dos problemas humanitários mais graves do século XXI. Nem as cenas trágicas visualizadas pelos meios de comunicação, nem os dramas narrados por essas pessoas parecem ter despertado o interesse dos governantes dos países mais desenvolvidos, nem das organizações internacionais, para buscar uma solução que minimize esse fenômeno. Se pensarmos que a comunicação não se omite diante desse problema, talvez devamos pensar nos motivos pelos quais se instaura essa anestesia social. A sua pergunta me parece que dá a pista mais adequada para responder a tal problema. Não é o outro que me incomoda, mas o que ele representa em termos existenciais e de valores, ou seja, me afeta nas minhas crenças e no meu modo de vida. Se agregarmos o fato de que essas pessoas procedem de países considerados mais empobrecidos, acrescenta-se uma dose 


\section{ANO 15 • NÚMERO 28 • 1ํㅗN. 2018 • ORGANICOM}

de inferioridade no que essas pessoas podem trazer ou agregar para o país que as acolhe. Aliás, na maioria das vezes, são acusadas como culpadas pelos problemas que os países teriam que enfrentar (violência, desemprego, marginalização, pobreza...) com ou sem imigração. Agora, se a comunicação pauta a sociedade, devemos ficar muito atentos ao modo como isso é feito. Como são apresentadas e representadas essas pessoas e com qual finalidade? Tais abordagens visam realizar ações assistenciais ou de acolhida com dignidade e com respeito? Ora, é difícil imaginar que essas pessoas não exercessem uma atividade no seu país de origem. Paulo Freire falava que todos nós sabemos algo, ninguém não sabe nada, razão pela qual não se trata de acolher simplesmente - embora só isso já seria um grande feito e tenha um grande valor -, e sim de propiciar o exercício da cidadania na sua plenitude. Há uma questão que me incomoda nos meios de comunicação. Dificilmente se aprofundam nos motivos pelos quais essas pessoas têm para motivá-las a abandonar seu lar e procurar uma vida mais digna em um lugar que para elas é estranho e de difícil compreensão. Sem dúvida, ao expor essa situação, se atingiria a causa do problema e, talvez, se encontrariam responsabilidades graves dos países mais desenvolvidos como sendo causadores das grandes migrações. Entretanto, como os meios de comunicação fazem parte desse grande bloco que interpreta os fatos a seu modo, essa questão passa despercebida ou, como já tínhamos falado, é manipulada e maquiada de tal forma que a opinião pública apenas fica sabendo superficialmente. São pessoas que vêm de países empobrecidos, mas debater a razão disso é um item que a comunicação massiva, definitivamente, não oferece espaço e oportunidade para os cidadãos discutirem.

ORGANICOM - Eloísa, atualmente você vem desenvolvendo seus trabalhos de pesquisa e docência na perspectiva da Comunicação para a Igualdade. Quais são seus princípios e objetivos? Acredita que esse debate e disciplina acadêmica no ensino superior poderiam ser aplicados em vários cursos universitários?

Eloísa - Começo pela segunda parte da pregunta: com certeza! Os próprios estudantes, ao finalizarem os cursos, produzem esta conclusão: uma disciplina como essa, que trabalha na perspectiva crítica dos futuros profissionais em termos de antecipar as consequências culturais no coletivo de nossas ações, seria necessária em todos os programas de estudos universitários. Abre a mente, rompe pré-concepções, permite conhecer outras lógicas e propostas invisibilizadas, frequentemente, no currículo acadêmico do ensino superior. 0 objetivo principal da disciplina, na realidade, é capacitar na eficácia cultural de nossas ações (comunicativas), na capacidade de articular e influenciar positivamente na transformação da violência cultural e de facilitar processos mobilizadores, transformadores e transgressores a partir da não violência. Sempre é possível abordar as realidades partindo do interesse comum.

Em conclusão, como dizíamos anteriormente sobre a Comunicação para a Paz, a Comunicação para a Igualdade é outra "camiseta política" que colocamos à comunicação para visibilizar a importância do feminismo e da interseccionalidade para uma comunicação mobilizadora e transgressora para a transformação social em direção à justiça global. Uma comunicação orientada para denunciar e transformar, partindo de propostas concretas e com ênfase nos êxitos já alcançados, essas violências culturais que deixam opacas as relações desiguais e abusivas de poder. Uma comunicação contra-hegemônica, mas como ressonância cultural que persegue a eficácia e a eficiência cultural, partindo de processos coletivos, participativos e cooperativos que considera o poder narrativo, mas também o desafio da sustentabilidade cultural (os tempos educativos dos quais falava Jesús Martín-Barbero e que Javier Erro Sala recupera).

ORGANICOM - Max, considerando sua experiência de pesquisa sobre a Nova Ordem Internacional a partir de estudos sobre as Epistemologias do Sul, de Boaventura de Sousa Santos, quais as contribuições dessa perspectiva para os estudos em comunicação? Você acredita que essa proposta (que nasce a partir das "vozes do Sul global") se aproxima de um debate crítico em diálogo com a Comunicação para a Paz (que nasceu a partir dos "olhares do Norte global")? Há pontos de convergência? 
Max - 0 pensamento de Boaventura de Souza Santos é vastíssimo e abrange praticamente todas as áreas do saber no campo das humanidades. Partindo de questões que venho desenvolvendo em minha pesquisa, identifico que a ideia mais forte que ele defende é que o modelo econômico, político, ideológico, social e cultural proposto pelo Norte global fracassou totalmente. 0 que tal modelo criou para o restante do mundo é o desemprego, a exploração, a miséria, a desigualdade, a concentração de renda, a intolerância, entre outros. Enfim, nesse contexto, podemos reconhecer que já passou da hora de buscar uma alternativa capaz de oferecer uma nova esperança para os deserdados da Terra. 0 importante é pensar que, se o Norte global fracassou, a solução deve ser buscada em outros lugares e, justamente nessa busca, Boaventura nos propõe que olhemos com muito carinho para as experiências do Sul global. Mais uma vez, vale destacar que essa nomenclatura Norte/Sul não se refere unicamente a áreas geográficas por estarem assentadas em outra concepção de mundo, tal como entendida pelos mais empobrecidos e que colocam valores como a solidariedade, o respeito, a diversidade, a tolerância - entre muitos outros que poderíamos citar - na base de sua atuação. Assim, se criariam novas diretrizes para elaborar um novo modelo de sociedade. Dessa forma, novos agentes entrariam em cena e outro mundo seria possível, como se defende nos Fóruns Sociais Mundiais. Agora, sabemos que a comunicação massiva não "compra" essas ideias e muito menos dá visibilidade às inúmeras experiências bem-sucedidas, nas quais se aplicaram tais princípios procedentes das experiências do Sul. Contudo, podemos nos perguntar se essa perspectiva crítica tem relação com os estudos críticos da Peace Research? Com toda certeza, sim! Aliás, esse pode ser um caminho de transformação, tanto no Norte como no Sul global, para se elaborar uma nova agenda em sociedade, uma vez que estamos falando de práxis guiadas pelos valores da paz e da sustentabilidade, que negam veementemente a ideia do lucro em todas as suas dimensões. 0 que se define na Nova Ordem Mundial são, justamente, as formas mais requintadas pelas quais o capitalismo opera na contemporaneidade e como é necessário denunciá-las, pois aparecem como "cordeiros vestidos em pele de lobo". Sobre essa questão, apenas dou um exemplo: quem mais defende a preservação da agua é a indústria dos refrigerantes. Poderíamos pensar que possuem uma grande consciência ecológica quando, na verdade, estão apenas preservando a fonte de seus negócios. Justamente contra esse tipo de ações é que se constroem novas formas de pensar, mais abrangentes e que apontam para um futuro diferente, melhor e que centralize suas ações visando às pessoas, não o lucro, a exploração ou a reprodução do capital que estão ameaçando, inclusive, a sobrevivência do planeta.

ORGANICOM - Eloísa, como ex-diretora do Programa de Pós-graduação (Mestrado e Doutorado Internacional) em Estudos para a Paz, Conflitos e Desenvolvimento vinculado à Cátedra Unesco de Filosofia para a Paz da Universitat Jaume I(Espanha), qual é sua visão sobre a relevância de programas de pós-graduação dirigidos à formação em Peace Studies? Por que se busca a interculturalidade dos estudantes e do professorado que formam parte desses programas? Ao mesmo tempo, quais obras considera relevantes para os que desejam iniciar seus estudos em Comunicação para a Paz?

ELOÍSA - Primeiramente, cabe pontuar que conviver na diferença somente se pode aprender a partir da prática. Aprender a discordar e a colaborar apesar das dificuldades e complexidades é um desafio que somente a pluralidade de experiências e perspectivas interdisciplinares permite construir. Nesse sentido, uma vez mais, a família de adjetivos para definir o campo da Comunicação para a Paz é ampla e diversa. Juntando a Comunicação para a paz, para o desenvolvimento e a transformação de conflitos e da transformação social, reúno uma lista muito heterogênea de distintas possibilidades de iniciação à Peace Research. São somente alguns (deixo muitos de fora) dos trabalhos que eu tenho encontrado e utilizado mais (ou projetos coletivos nos quais tenho participado para tratar de difundir estas ideias), como: obra inicial, outros textos introdutórios, artigos recentes em periódicos, trabalhos coletivos, olhares panorâmicos e um vídeo de Xavier Giró. 
Max - Antes de tudo, devo a esse convite o despertar para esse tipo de ideias, pois, sou um testemunho vivo da eficiência e da necessidade de se ter esse tipo de programas na Espanha, no Brasil ou em qualquer lugar do mundo. A importância da pós-graduação reside na formação de pessoas qualificadas nesses temas e que, provavelmente, ocuparão postos de decisão na sociedade. Portanto, a possibilidade de multiplicar os princípios dos Estudos para a Paz é evidente. Como comentei e gostaria de destacar, isso vem acontecendo muito no âmbito da educação, mas aos poucos está entrando com bastante força no campo da saúde. Dito isso, deixo registrado meu otimismo em relação ao enorme potencial que essas ações carregam. 